\title{
ISLAM NUSANTARA: \\ Sebuah Alternatif Model Pemikiran, Pemahaman, dan Pengamalan Islam
}

\author{
Mujamil Qomar \\ IAIN Tulungagung \\ Email:mujamil65@yahoo.com
}

\begin{abstract}
Islam Nusantara is a model of thought, comprehension, and implementation of Islamic teachings covered by culture and tradition developed in Southeast Asia (the scope of which is limited to Indonesia), that reflects Islamic identity with methodological nuance. The identity has various and controversial responses when it is socialized among Moslem because Islam is one, namely, Islam taught by prophet Muhammad. Otherwise, the majority of Islamic scholars accepted Islam Nusantara. That Islam is one is substantively true, but it expressed widely including Islam Nusantara. Islam is presented (thought, comprehended, and implemented) through cultural approach. The result leads to the thinking model, comprehending, and implementing Islamic teachings which are harmonious, moderate, inclusive, tolerant, peaceful, and multicultural based. The diverse Islamic thought is caused by local culture, especially Javanese culture, or called cultural acculturation. The Indonesian Islam can be a role model. It brings peaceful and harmonious messages, so it could be socialized internationally and replaced misleading opinion that Islam is full of violence.
\end{abstract}

Islam Nusantara merupakan model pemikiran, pemahaman dan pengamalan ajaran-ajaran Islam yang dikemas melalui pertimbangan budaya atau tradisi yang berkembang di wilayah Asia Tenggara (tetapi kajian ini dibatasi pada Indonesia), sehingga mencerminkan identitas Islam yang bernuansa metodologis. Identitas ini ketika disosialisasikan di kalangan umat Islam, khususnya para pemikirnya direspons dengan tanggapan yang kontroversial: ada yang menolak identitas Islam Nusantara itu karena Islam itu hanya satu, yaitu Islam yang diajarkan oleh Nabi. Sebaliknya, banyak pemikir Islam yang menerima identitas Islam 
Nusantara itu. Bagi mereka, Islam hanya satu itu benar secara substantif, tetapi ekpresinya beragam sekali, termasuk Islam Nusantara. Islam ini ditampilkan (dipikirkan, dipahami dan diamalkan) melalui pendekatan kultural. Hasilnya melahirkan model pemikiran, pemahaman dan pengamalan ajaran-ajaran Islam yang ramah, moderat, inklusif, toleran, cinta damai, harmonis, dan menghargai keberagaman. Keberagamaan Islam demikian ini terjadi lantaran perjumpaan Islam dengan budaya (tradisi) lokal, khususnya Jawa, yang biasa disebut akulturasi budaya. Islam Indonesia patut menjadi contoh cara berislam yang demikian. Model Islam yang serba menyejukkan ini perlu dipublikasikan secara internasional dan diharapkan mampu menggugurkan persepsi dunia bahwa Islam itu penuh kekerasan.

Keywords: Islam, Nusantara, Indonesia

\section{Pendahuluan}

Dalam tataran praktis, sebenarnya tipologi Islam Nusantara telah lama terwujud di wilayah Nusantara. Sebuah model pemikiran, pemahaman dan pengamalan ajaran-ajaran Islam dengan mempertimbangkan tradisi atau budaya lokal, sehingga dalam hal-hal di luar substansi, mampu mengekpresikan model berislam yang khas Nusantara dan membedakan dengan model berislam lainnya baik di Timur Tengah, India, Turki dan sebagainya. Secara konseptual, identitas Islam Nusantara ini telah ditulis oleh beberapa penulis, antara lain: Azyumardi Azra (2015) dengan judul Islam Nusantara Jaringan Global dan Lokal dan Nor Huda (2013) dengan judul Islam Nusantara Sejarah Sosial Intelektual Islam di Indonesia. Maka istilah Islam Nusantara bukanlah istilah baru, melainkan telah dikenal cukup lama, termasuk yang diperkenalkan kedua penulis tersebut. Hanya saja, kedua penulis ini menjelaskan Islam Nusantara ini dari segi tinjauan historis, belum banyak menyentuh tinjauan metodologis.

Beberapa tahun terakhir, Islam Nusantara menjadi lebih populer karena dijadikan tema utama Muktamar Nahdatul Ulama (NU) ke-33 di Jombang Jawa Timur yang berlangsung pada 1-5 Agustus 2015. Sementara NU mewakili umat Islam mainstream Indonesia, Islam Nusantara makin terpublikasikan dalam masyarakat Muslim Indonesia yang lebih luas, menembus masyarakat perkotaan hingga pedesaan. Penentuan tema utama Islam Nusantara dalam muktamar tersebut sebagai respons terhadap citra Islam di pentas internasional yang semakin merosot bahkan cenderung dinilai negatif, lantaran kasus-kasus kekerasan yang dilakukan dengan mengatasnamakan Islam, baik pembunuhan, penyanderaan, pemboman dan sebagainya. 
Identitas pelaku tindakan radikal dan pengatasnamaan Islam tersebut melahirkan anggapan yang salah bahwa Islam itu mengajarkan kekerasan, pertumpahan darah, tindakan keji, perlakuan kejam dan sadis, perbuatan barbar, dan tindakan-tindakan dehumanisasi lainnya. Padahal Islam lebih banyak mengajarkan kedamaian, kerukunan, keharmonisan, toleransi, dan keterbukaan. Sayangnya ajaran-ajaran yang indah dan sejuk ini kurang ditonjolkan, sehingga kurang dikenal oleh dunia internasional. Demikian pula, mayoritas umat Islam justru lebih mengutamakan kedamaian daripada kekerasan. Uniknya, tindakan kekerasan yang dilakukan oleh segelintir umat Islam inilah yang mengundang perhatian negatif-pejoratif dari masyarakat internasional, kemudian dijustifikasi sebagai karakteristik Islam.

Tujuan penulis mengkaji Islam Nusantara dalam tulisan ini adalah berusaha menghadirkan salah satu alternatif model pemikiran, pemahaman dan pengamalan ajaran-ajaran Islam yang humanis dan ramah, baik dalam lingkup geografis, sosial maupun budaya. Sebagai istilah baru, bagi kebanyakan umat Islam Indonesia, Asia Tenggara maupun dunia, makna Islam Nusantara perlu mendapatkan penjelasan yang cukup agar mudah dalam memahaminya.

\section{Makna Islam Nusantara}

Upaya pemaknaan memberikan kontribusi yang besar bagi upaya memahami hakekat Islam Nusantara. Sebagai hakekat, sulit dipahami tanpa mengetahui ciri atau karakteristiknya. Selanjutnya makna tersebut memberikan pemahaman awal pada seseorang yang berusaha memahami substansinya. Dengan kata lain, makna Islam Nusantara berfungsi membuka jalan awal bagi pemahaman seseorang dalam menggali dan mengkaji pemikiran, pemahaman dan pengamalan ajaran-ajaran Islam yang mencerminkan dan dipengaruhi oleh kawasan ini.

Ada beberapa definisi tentang Islam Nusantara yang dikemukakan oleh pemikir-pemikir Islam, antara lain: "Islam Nusantara ialah paham dan praktek keislaman di bumi Nusantara sebagai hasil dialektika antara teks syariat dengan realitas dan budaya setempat." (Muhajir dalam Sahal \& Aziz, 2015: 67). Pemaknaan senada, "Islam Nusantara adalah Islam yang khas ala Indonesia, gabungan nilai Islam teologis dengan nilai-nilai tradisi lokal, budaya, adat istiadat di tanah air" (Bizawie dalam Sahal \& Aziz, 2015: 239). Definisi pertama ini menunjukkan bahwa secara substantif, Islam Nusantara merupakan paham Islam dan implementasinya yang berlangsung di kawasan Nusantara sebagai akibat sintesis antara wahyu dan budaya lokal, sehingga 
memiliki kandungan nuansa kearifan lokal (local wisdom). Sedangkan definisi kedua merupakan Islam yang berkarakter Indonesia, tetapi juga sebagai hasil dari sintesis antara nilai-nilai Islam teologis dengan nilai-nilai tradisi lokal. Hanya saja, wilayah geraknya dibatasi pada wilayah Indonesia, sehingga lebih sempit daripada wilayah gerak dalam pengertian yang pertama yang menyebut bumi Nusantara. Sayangnya, dalam sumber-sumber tersebut bumi Nusantara tidak dijelaskan wilayah jangkauannya.

Selanjutnya, terdapat pemaknaan Islam Nusantara yang ditekankan sebagai metodologi dakwah yang berbeda dengan pemaknaan yang pertama maupun kedua.

"Islam Nusantara adalah metodologi dakwah untuk memahamkan dan menerapkan universalitas (syumuliyah) ajaran Islam sesuai prinsip-prinsip Ahlussunnah waljama'ah, dalam suatu model yang telah mengalami proses persentuhan dengan tradisi baik ('urf shahih) di Nusantara, dalam hal ini wilayah Indonesia, atau merupakan tradisi tidak baik ('urf fasid) namun sedang dan/atau telah mengalami proses dakwah amputasi, asimilasi, atau minimalisasi, sehingga tidak bertentangan dengan diktum-diktum syari'ah" (Anam, t.t: 22).

Definisi tersebut, dari segi skala berlakunya memiliki kesamaan seperti definisi kedua. Namun, definisi ini mengandung penekanan, di samping pada metodologi dakwah, juga pada universalitas ajaran Islam, prinsipprinsip ahlussunnah waljama'ah, dan proses dakwah amputasi, asimilasi, atau minimalisasi untuk mensterilkan metodologi dakwah itu dari tradisi-tradisi lokal yang menyesatkan. Alur berpikir yang tercermin dalam definisi ketiga itu juga kurang jelas, untuk tidak dikatakan kacau, sehingga tidak mudah dipahami kecuali dilakukan telaah secara cermat dan teliti, karena alur berpikirnya yang berkelok-kelok.

Adapun pada bagian lain terdapat upaya memperluas wilayah pemberlakuan Islam Nusantara hingga mencapai kawasan Asia Tenggara. Islam Nusantara mengacu pada gugusan kepulauan atau benua maritim (Nusantara) yang mencakup Indonesia, wilayah Muslim Malaysia, Thailand Selatan (Patani), Singapura, Filipina Selatan (Moro), dan Champa (Kampuchea) (Azra dalam Sahal \& Aziz, 2015: 169). Maka Islam Nusantara sama sebangun dengan 'Islam Asia Tenggara' (Southeast Asian Islam).

Dari segi ruang lingkup Islam Nusantara, Muhajir tidak memberikan batasan berlakunya secara jelas, Bizawie dan Anam hanya membatasi pada wilayah Indonesia, maka Azra memperluas wilayah berlakunya tersebut meliputi kawasan Muslim seluruh Asia Tenggara. Namun, disayangkan Azra tidak 
menjelaskan hakekat istilah Islam Nusantara tersebut. Penulis sependapat dengan upaya memperluas cakupan Islam Nusantara hingga mencapai Asia Tenggara sebagaimana diungkapkan oleh Azra, namun dalam pembahasan berikutnya penulis hanya membatasi pada Islam yang berkembang di wilayah Indonesia.

Berdasarkan pertimbangan empat definisi tersebut, dapat ditegaskan bahwa Islam Nusantara yang dimaksudkan di sini adalah merupakan model pemikiran, pemahaman, dan pengamalan ajaran-ajaran Islam yang dikemas melalui budaya maupun tradisi yang berkembang di wilayah Asia Tenggara. Adapun dari segi komponen keislamannya, "Ortodoksi Islam Nusantara adalah kalam (teologi) Asy'ariah, fiqh Syafi'i, dan tasawuf al Ghazali” (Azra dalam Sahal \& Aziz, 2015: 172). Disamping tiga komponen ini, dapat ditambah tiga komponen lagi untuk memperkokoh konsep Islam Nusantara, yaitu komponen politik, pendidikan, dan budaya. Maka objek kajian Islam Nusantara itu setidaknya harus meliputi enam komponen, yaitu kalam (teologi), figh, tasawuf, politik, pendidikan, dan budaya (tradisi).

Demikianlah sekilas pemaknaan Islam Nusantara yang saat ini mendapat perhatian yang cukup besar, khususnya bagi umat Islam di Indonesia. Perhatian mereka terbelah dalam merespon kehadiran dan keberadaan Islam Nusantara, sehingga memunculkan kontroversi antara kelompok yang pro dan kontra.

\section{Respons Umat Islam Terhadap Islam Nusantara}

Sosialisasi identitas Islam Nusantara ternyata mendapat respons yang beragam di kalangan umat Islam terutama para pemikirnya. Terjadi kontroversi pandangan dan penilaian di kalangan mereka hingga terbelah menjadi beberapa kelompok, setidaknya ada empat kelompok. Menurut Sahal (dalam Sahal \& Aziz, 2015: 16), Islam Nusantara yang dijadikan tema utama Muktamar NU itu telah menimbulkan debat publik yang serius. Kesaksian senada diungkapkan oleh Fatoni (dalam Sahal \& Aziz, 2015: 229). Ada sikap pro dan kontra terhadap Islam Nusantara di kalangan mereka; ada yang berjuang keras dan berargumentasi dengan mendayagunakan penalarannya agar Islam Nusantara bisa diterima baik di kalangan umat Islam maupun non Islam, sebaliknya ada yang menghadang perjuangan itu dan berusaha mematahkan argumentasinya; ada yang memiliki harapan besar dengan kehadiran Islam Nusantara itu, namun ada yang justru menaruh berbagai kecurigaan sebagai rekayasa yang canggih dari Barat; ada yang kurang menyetujui Islam Nusantara itu tetapi mereka diam, tidak melakukan serangan-serangan yang berusaha mematahkan 
argumentasi kelompok yang menyetujui Islam Nusantara; dan ada juga yang menyetujui penggunaan istilah Islam Nusantara tersebut, namun bersikap diam dan pasif sehingga tidak berusaha mempromosikannya.

Mereka yang menolak Islam Nusantara memiliki pandangan bahwa Islam itu hanya satu. Islam yang satu itu merupakan Islam yang diajarkan oleh Nabi Muhammad SAW. Islam tidak bisa diberikan identitas berdasarkan suatu pendekatan, corak, peranan maupun kawasan sehingga membentuk identitas Islam khusus seperti Islam Nusantara itu. Kalau terdapat Islam lain di luar Islam yang diajarkan oleh Nabi Muhammad itu harus segera menyesuaikan diri dengan Islam standar tersebut, sehingga keunikan identitas Islam tertentu justru dipandang negatif karena telah melakukan penyimpangan dari format Islam yang ideal (Islam yang sebenarnya). Keunikan Islam Indonesia sedang menghadapi gugatan seiring dengan kehadiran fenomena radikalisme belakangan ini (Rahmat dalam Rahmat et al., 2003: xvi). Pemahaman keagamaan mainstream umat Islam Indonesia dinilai sebagai pemahaman yang salah, karena berbeda dengan Islam ideal, Islam yang dicontohkan oleh salaf al-shalih. Keunikan ekpresi keislaman masyarakat Indonesia dicerca sebagai 'jahiliyah modern' yang menyimpang dari Islam yang benar, otentik, dan asli. Otensitas Islam hilang ketika bercampur dengan unsur luar, termasuk unsur Nusantara.

Islam senantiasa satu kapan pun dan dimanapun. Islam tidak akan mengalami perubahan meskipun menghadapi masa modern sekalipun, dan Islam juga tidak akan mengalami perubahan ketika agama yang dibawa Nabi Muhammad ini disebarluaskan dan dikembangkan di luar Makkah, termasuk misalnya ketika disebarkan dan dikembangkan di Indonesia. Ada pandangan seolah-olah Islam Indonesia itu berbeda dengan Islam kawasan lain (Langgulung dalam Azhari \& Saleh, 1989: 157). Islam adalah Islam dimana saja berada. Jadi, sifat Islam itu mutlak, kekal, dan abadi. Kemungkinan berbeda hanya pada tataran pelaksanaannya. Ketiga sifat Islam itulah yang mengawal kesatuan identitas Islam sehingga Islam berada dimanapun dan kapanpun tetap sebagai Islam seperti Islam yang diajarkan oleh Nabi Muhammad SAW.

Pada bagian lain dalam posisi yang berlawanan dengan pandanganpandangan yang menolak Islam Nusantara itu, terdapat beberapa pemikir yang justru menyetujuinya. Azra (dalam Sahal \& Aziz, 2015: 171-172) menyatakan bahwa Islam satu itu hanya ada pada level al Quran. Namun al Quran (serta hadits) membutuhkan rumusan yang rinci, sehingga ayat-ayatnya perlu ditafsirkan dan dijelaskan maksudnya. Hasilnya berupa kemunculan penafsiran dan penjelasan yang berbeda-beda, kemudian menjadi madzhab atau aliran. Inilah 
menurut penulis, realitas yang kita hadapi dan harus kita sadari. Islam satu itu hanya terdapat pada substansi ajarannya, tetapi penampilan luarnya sangat beragam. Sebagaimana menjadi acuan Muhammad, Qatadah menyatakan al-din wahid wa al-syari'ah mukhtalifah/agama hanya satu, sedangkan syariat berbeda-beda (dalam Sahal \& Aziz, 2015: 98). Agama di sini yang dimaksudkan adalah agama Islam.

Selanjutnya, dukungan terhadap identitas Islam Nusantara mendapat dukungan semakin kuat dari beberapa pemikir Islam lainnya dan jumlahnya lebih banyak. Ali (2006: 10) menjelaskan bahwa Islam itu satu. Tetapi, ketika Islam telah membumi, pemahaman dan ekpresi umatnya sangat beragam. Fanani (2004: 116) menyatakan bahwa fenomena keberagamaan umat dewasa ini mengalami pendulum yang sangat berwarna-warni. Sehingga, Islam tidak dipandang lagi secara tunggal, melainkan majemuk (Rahmat Rahmat et al., 2003: xx-xxi), Sobarna (2008: v) menyatakan bahwa Islam itu satu, tetapi dalam mengkajinya ada dua wajah yang biasanya dikemukakan dengan berbagai ekspresi. Shihab (1998: 249) mensinyalir bahwa cendekiawan kontemporer memperkenalkan Islam regional dan Islam universal. Adapun Ma'arif (2009: 181) mengungkapkan dalam sub bab bukunya dengan bahasa yang indah, "sebuah Islam, seribu satu ekpresi."

Bagi pemikir-pemikir Islam yang mendukung identitas Islam Nusantara ini tampaknya mereka memandang bahwa substansi Islam memang satu, namun ekpresinya sangat beragam. Ketika mereka mengakui keberadaan identitas Islam Nusantara, mereka hanya memandang identitas Islam itu dari tinjauan ekpresinya. Ekpresi Islam Nusantara ini ketika menunjukkan fenomena-fenomena yang sama secara berkesinambungan dari generasi ke generasi berikutnya, pada gilirannya akan membentuk karakteristik-karakteristik tertentu yang dapat diidentifikasi, diketahui dan dipahami sehingga memudahkan orang lain dalam memahami Islam Nusantara tersebut.

\section{Karakteristik Islam Nusantara}

Islam Nusantara ini memiliki karakteristik-karakteristik yang khas sehingga membedakan dengan karakteristik-karakteristik Islam kawasan lainnya, khususnya Islam Timur Tengah yang banyak mempengaruhi Islam di berbagai belahan bumi ini. Wilayah Nusantara memiliki sejumlah keunikan yang berbeda dengan keunikan di negeri-negeri lain, mulai keunikan geografis, sosial politik dan tradisi peradaban (Ghozali dalam Sahal \& Aziz, 2015: 115). Keunikan-keunikan ini menjadi pertimbangan para ulama ketika menjalankan 
Islam di Nusantara. Akhirnya, keunikan-keunikan ini membentuk warna Islam Nusantara yang berbeda dengan warna Islam di Timur Tengah. Islam Nusantara merupakan Islam yang ramah, terbuka, inklusif dan mampu memberi solusi terhadap masalah-masalah bangsa dan negara (Bizawie dalam Sahal \& Aziz, 2015; 240). Islam yang dinamis dan bersahabat dengan lingkungan kultur, sub kultur, dan agama yang beragam. Islam bukan hanya dapat diterima masyarakat Nusantara, tetapi juga layak mewarnai budaya Nusantara untuk mewujudkan sifat akomodatifnya, yakni rahmatan li al'alamin. Pesan rahmatan li al'alamin ini menjiwai karakteristik Islam Nusantara, sebuah wajah yang moderat, toleran, cinta damai, dan menghargai keberagaman (Bizawie dalam Sahal \& Aziz, 2015: 242). Islam yang merangkul bukan memukul; Islam yang membina, bukan menghina; Islam yang memakai hati, bukan memaki-maki; Islam yang mengajak tobat, bukan menghujat; dan Islam yang memberi pemahaman, bukan memaksakan.

Semenjak awal, Islam Indonesia memiliki corak dan tipologi tersendiri, yaitu Islam yang ramah dan moderat dan merupakan Islam garis tengah yang menganut landasan ideologi dan filosofis moderat (Sucipto, 2007: 18). Arus besar yang diwakili NU dan Muhammadiyah telah menjadi merek paten bagi gerakan Islam moderat, modern, terbuka, inklusif, dan konstruktif (Ma'arif, 2009: 304). Moderasi dan toleransi menjadi karakteristik mainstream anggota kedua organisasi tersebut (Bruinessen dalam Samuel dan Norddholt, 2004: 61). NU dan Muhammadiyah berperan sebagai penjaga gawang moderasi (Qomar, 2013: 153). Moderasi NU dan Muhammadiyah ini mewarnai corak Islam Nusantara selama ini. Sebab dua organisasi Islam terbesar ini merupakan simbol Islam Nusantara, kendatipun ada juga organisasi Islam yang radikal maupun liberal, tetapi keduanya sangat kecil sehingga tidak patut menjadi kelompok mainstream yang mewakili Islam Nusantara.

Islam moderat itu memiliki misi untuk msenjaga keseimbangan antara dua macam ekstrimitas, khususnya antara pemikiran, pemahaman dan gerakan Islam fundamental dengan liberal, sebagai dua kutub ekstrimitas yang sulit dipadukan. Maka Islam moderat memelihara dan mengembangkan kedamaian holistik, yakni kedamaian sesama umat Islam maupun dengan umat-umat lainnya, sehingga Islam moderat membebaskan masyarakat dari ketakutan. Islam moderat menawarkan wacana pembebasan yang mencerahkan, sebab tidak berpijak pada pendekatan kekerasan dan ketergesa-gesaan (Basya dalam Sucipto, 2007: 392). Islam moderat juga merupakan upaya menyelamatkan kondisi dunia sekarang ini (Imarah dalam Sucipto, 2007: 443). Peradaban 
Islam moderat dibangun dari kombinasi akal, intuisi, wahyu, syariat, dan keimanan pada dua kitab, yaitu kitab yang tertulis (al Quran) dan kitab yang terbuka (alam semesta).

Oleh karena itu, Islam moderat mampu bergerak secara fleksibel dalam menghadapi tantangan apa pun. Islam moderat juga mampu merespons tradisi yang telah mengakar di masyarakat, sehingga Islam moderat bertindak bijaksana. Historiografi lokal perlu diperhitungkan dalam proses islamisasi dan intensifikasi pembentukan identitas dan tradisi Islam di Nusantara (Azra, 2002: 15), sebab masyarakat Muslim lokal juga memiliki jaringan kesadaran kolektif (network of collective memory) tentang proses islamisasi yang berlangsung di kalangan mereka, kemudian terekam dalam berbagai historiografi lokal. Proses islamisasi di Indonesia terjadi dengan proses yang sangat pelik dan panjang. Penerimaan Islam penduduk pribumi, secara bertahap menyebabkan Islam terintegrasi dengan tradisi, norma dan cara hidup keseharian penduduk lokal (Huda, 2013: 61). Perjumpaan keduanya menyebabkan terjadinya proses saling mengambil dan memberi (take and give) antara ajaran Islam yang baru datang dengan tradisi lokal yang telah lama mengakar di masyarakat.

Akhirnya, Islam dan tradisi lokal itu bertemu dengan masyarakat secara individual maupun kolektif, tanpa bisa diklasifikasikan secara jelas mana yang Islam dan mana produk lokal, sehingga tradisi itu berkembang, diwariskan dan ditransmisikan dari masa lalu ke masa kini (2008: viii). Implikasinya, tradisi Islam lokal hasil konstruksi ulang itu memiliki keunikan yang khas: ia tidak genuin Islam, tidak genuin Kejawen, dan tidak juga genuin lainnya (Khalil, 2008: ix), sebab keduanya (Islam dan tradisi lokal) benar-benar telah menyatu menjadi satu kesatuan, sebagai tradisi baru yang menyerap unsur-unsur dari keduanya. Fenomena inilah yang biasanya disebut akulturasi budaya.

Dalam konteks Islam Nusantara ini, akulturasi yang paling dominan terjadi antara Islam dengan budaya (tradisi) Jawa, sebab keduanya sama-sama kuat. Kebudayaan dan tradisi Jawa di masa silam, sejak berdiri dan kejayaan kerajaan Demak, Pajang hingga Mataram tetap mempertahankan tradisi Hindu-Budha dan Animisme-Dinamisme sebagai produk budaya pra HinduBudha (Khalil, 2008: 149). Tradisi ini diperkaya dan disesuaikan dengan nilai-nilai Islam. Istana kerajaan Pajang dan Mataram bernuansa Islam, tetapi adat istiadat masih dipertahankan (Hariwijaya, 2006: 206). Gambaran Islam lokal ini terjadi pada masa lampau, dan realitasnya masih terpateri secara jelas hingga sekarang ini. Banyak sekali budaya, tradisi, dan adat istiadat lokal yang diwarnai Islam terus berkembang, dan sebaliknya juga banyak pemahaman 
serta pengamalan ajaran Islam yang dipengaruhi oleh budaya dan tradisi lokal yang telah berkembang dan mengakar di masyarakat.

Adanya perjumpaan Islam dengan tradisi lokal itulah yang menjadi penyebab utama proses saling menyesuaikan. Kehadiran Islam secara damai mempengaruhi akulturasi budaya antara budaya lokal dengan Islam (Yusuf dan Haris, 2014: 1). Adanya saling mengisi antara keduanya mewujudkan budaya baru baik fisik maupun non fisik. Budaya itu kemudian menjadi ciri khas budaya masyarakat Islam Indonesia. Bahkan, tidak ada satu pun agama yang bebas dari tradisi panjang yang dihasilkan masyarakat pemeluknya (Machasin, 2011: 185-186). Maka Islam yang dipahami dan dijalankan oleh orang Jawa secara praktis berbeda dengan Islam yang dipahami dan dihayati oleh orang-orang Sunda. Dalam skala yang lebih luas lagi, Islam yang dihayati orang-orang Timur Tengah, dalam batas tertentu, berbeda dengan Islam yang dihayati bangsa Indonesia. Sedangkan tradisi, tidak pernah statis atau berhenti (Ramadan, 2010: 146). Tradisi senantiasa berkembang terutama melalui peralihan generasi mendatang yang menjadi bagian darinya. Tradisi mentransmisikan nilai, norma, budaya dan jalan hidup.

Ada pun sikap Islam dalam menghadapi budaya atau tradisi lokal dapat dipilah menjadi tiga: (1) menerima dan mengembangkan budaya yang sesuai dengan prinsip-prinsip Islam dan berguna bagi pemuliaan kehidupan umat manusia; (2) menolak tradisi dan unsur-unsur budaya yang bertentangan dengan prinsip-prinsip Islam; dan (3) membiarkan saja seperti cara berpakaian (Machasin, 2011: 187). Sikap pertama didasari pertimbangan bahwa budaya lokal bermanfaat daan mendukung perbaikan dan penyejahteraan masyarakat, sikap kedua karena budaya lokal dipandang membahayakan masyarakat, sedangkan sikap ketiga lantaran budaya yang dihadapi Islam tidak membahayakan mereka, meskipun juga tidak memberikan manfaat yang berarti kepadanya.

Oleh karena itu, perkembangan mayoritas kebudayaan Islam di Indonesia merupakan hasil dialog antara nilai-nilai Islam yang universal dengan ciri-ciri kultural kepulauan Nusantara (Madjid, 1996: 92). Islam berdialog secara damai dengan budaya lokal Nusantara yang berbeda sekali dengan budaya Arab dan ajaran Islam. Nuansa dialog yang damai juga dilakukan Islam dengan agama lokal animisme-dinamisme dan agama impor Hindu-Budha. Dialog damai itu terjadi, antara lain lantaran faktor pendekatan sufistik dalam menyebarkan Islam (Wijaya, 2011: 179). Pendekatan sufistik dalam melakukan dialog-religius tampaknya efektif karena pendekatan ini mampu mencairkan hubungan dan interaksi antarpemeluk agama, sehingga pemeluk Animisme, Dinamisme, 
Hindu dan Budha bisa cepat merapat pada ajaran Islam sebagai agama baru bagi mereka. Akhirnya sebagian besar mereka melakukan konversi agama menuju pangkuan Islam. Hasil dialog-religius yang interaktif inilah pada gilirannya yang memunculkan Islam Nusantara yang khas.

Di samping itu, substansi Islam Nusantara juga bisa dipahami dengan bantuan analisis faktor pembentuk lainnya, seperti faktor geografis. Sangat penting bagi orang yang mencoba memahami dan menjelaskan islamisasi di kawasan Nusantara untuk mempertimbangkannya (Azra dalam Sahal \& Aziz, 2015: 18). Jauhnya Nusantara menyebabkan islamisasi ini sangat berbeda dengan islamisasi di kawasan lain di Timur Tengah, Afrika Utara, dan Asia selatan. Lantaran posisi geografis yang jauh dari pusat penyebaran Islam tersebut, Indonesia terlambat dalam mengikuti proses islamisasi (Saleh dalam Wasim et al, 2005: 57). Indonesia sudah lama dipandang sebagai wilayah periferi Islam dunia, walaupun umat Islam Indonesia tidak pernah menyebut dirinya muallaf (Sychev, 2008: 11). Mereka memandang titik sentrum Islam adalah Makkah dan Madinah, namun ikatan dan keterpautan kedua wilayah itu bersama negara-negara Arab dan pusat-pusat Islam lainnya senantiasa kokoh. Gelombang kebangkitan Islam yang melanda Indonesia mulai 1970-an, makin mempersulit penggambaran Islam sekadar sebagai kekuatan marginal, yang terletak di pinggir-pinggir peradaban Indonesia (Woodward, 1996:34). Sejarah Indonesia modern sedang dalam proses menuju ke arah Islam santri (Maarif, 1993: 105). Islam abangan secara berangsur dan penuh kesadaran sedang menuju proses Islam santri. Proses ini berjalan dengan wajar dan damai. Ini menegaskan bahwa Islam Indonesia bukanlah agama yang statis, melainkan agama yang hidup penuh semangat dinamis (Nakamura, 1976: vi).

Keunikan dan potensi Indonesia belakangan ini memiliki daya tawar yang tinggi. Kalau dahulu Islam Indonesia dianggap sebagai Islam pinggiran, maka kini justru banyak pemikir Islam bereputasi internasional mengharapkan Indonesia tampil sebagai pemimpin dunia Islam, seperti Fazlur Rahman dan Malik Bennabi. Setidaknya, memang ada beberapa alasan timbulnya harapan itu. Indonesia memiliki jumlah penduduk Muslim terbesar di dunia, mengalami perkembangan demokrasi paling maju di antara negara-negara Muslim, memiliki kekayaan budaya yang luar biasa, memiliki tanah yang subur, dan posisi geografisnya jauh dari pusat konflik yaitu Palestina.

Posisi geografis ini mengandung nilai ganda. Di satu sisi Islam Indonesia seringkali dipandang "kurang Islam" lantaran interaksinya tidak bisa intern bersama Muslim Timur Tengah, namun di sisi lain posisi yang jauh dari Timur 
Tengah khususnya Palestina justru menguntungkan dari sisi keamanan politik. Disamping itu, posisi geografis ini juga harus menjadi pertimbangan khusus dalam melaksanakan syariat Islam.

"Suatu kesalahan manakala adat istiadat Makkah dipaksakan penerapannya di Indonesia. Alam Makkah berbeda dengan alam Indonesia, yang menyebabkan kondisi masyarakat Makkah berbeda dengan kondisi masyarakat Indonesia. Tingkat kemampuan orang Makkah belum tentu sama dengan kemampuan orang Indonesia. Suatu maslahat bagi orang Makkah belum tentu membawa maslahat bagi orang Indonesia. Demikian pula sebaliknya" (Ash-Shiddieqy dalam Shiddiqi, 1997: 231).

Karena itu, Islam Indonesia memiliki karakter khusus yang berlainan dengan Islam di kawasan lainnya, dalam batas-batas tertentu, disebabkan kondisi geografis.

Keunikan lainnya bagi Islam Nusantara, ditinjau dari perspektif agama, Indonesia adalah bangsa Muslim paling besar di dunia, namun secara religiopolitik dan ideologis, Indonesia bukanlah negara Islam (Madjid, 1996: 89). Kenyataan ini dipandang sebagai kejanggalan dan kelemahan umat Islam Indonesia menurut alur berpikir orang-orang Arab atau Timur Tengah. Sedangkan bagi pemikir-pemikir Islam Indonesia, itu justru sebagai kearifan mereka dalam menyiasati perpolitikan Indonesia. Negara Indonesia meskipun berpenduduk mayoritas Muslim, tetapi banyak juga orang-orang non-Muslim yang ikut berjuang merebut kemerdekaan Indonesia. Eksistensi mereka juga harus diperhatikan ketika Indonesia berhasil merdeka dan mendirikan Negara. Maka tokoh-tokoh Islam memandang bahwa yang terpenting ajaran-ajaran Islam dapat dijalankan dengan baik di bumi Indonesia ini tanpa harus secara formal menjadikan Negara Islam, karena mereka menekankan maqashid alsyari'ah. Cara demikianlah yang disepakati mayoritas Islam Indonesia.

Keunikan lainnya yang terdapat pada Islam Nusantara bahwa kendati pun sebagai salah satu bangsa Muslim terbesar di dunia, Indonesia merupakan bangsa yang paling sedikit mengalami arabisasi dibanding negara-negara Muslim lainnya (Madjid, 1996: 94). Kawasan Nusantara ini merepresentasikan salah satu bagian dunia Islam yang paling sedikit mengalami arabisasi. Namun, perkembangan Islam di Asia Tenggara tidak dapat dipisahkan dari perkembangan Islam di Timur Tengah (Azra, 2002: 90). Begitu akrabnya Islam dengan budaya (tradisi) lokal, Islam Nusantara tidak terlalu tertarik melakukan arabisasi. Misalnya dalam menggunakan pakaian shalat, mereka lebih suka memakai sarung dan songkok daripada jubah dan surban; dalam 
penyebutan tokoh agama, mereka lebih suka menyebut kiai, ajengan, tuan guru atau buya daripada syaikh maupun ulama; dalam menyebut tempat shalat, sebagian besar Muslim Indonesia lebih cenderung menyebut langgar daripada mushalla; dalam menyebut hari peringatan kelahiran institusi, mereka lebih suka menyebut dies natalis daripada dies maulidiyah; dan sebagainya.

Oleh karena itu, Islam Nusantara ini merupakan cara melaksanakan Islam melalui pendekatan kultural, sehingga merawat dan mengembangkan budaya (tradisi) lokal yang sesuai dengan ajaran Islam, dan berusaha mewarnai budaya (tradisi) lokal itu dengan nilai-nilai Islam manakala budaya (tradisi) tersebut masih belum senafas dengan Islam. Islam sangat menghargai kreasi-kreasi kebudayaan masyarakat, sejauh tidak menodai prinsip-prinsip kemanusiaan, ia tetap dipertahankan. Namun, jika budaya (tradisi) itu mencederai martabat kemanusiaan, ia harus ditolak. Maka Islam Nusantara ini tidak menghamba pada tradisi karena tidak kebal kritik. Hanya tradisi yang menghormati nilainilai kemanusiaan yang perlu dipertahankan (Ghazali dalam Sahal \& Aziz, 2015: 113). Mekanisme kerja Islam Nusantara ini melalui pendekatan adaptifselektif dengan menggunakan filter yang ketat terhadap budaya (tradisi) lokal yang telah mengakar di masyarakat. Dengan pendekatan ini, Islam diharapkan berperan aktif mempengaruhi budaya maupun tradisi lokal tersebut.

Kehadiran Islam Nusantara ini didasari motif tertentu yang sangat manusiawi dan adaptif, bukan konfrontatif. Dalam menggunakan istilah Islam Nusantara itu tidak ada sentimen terhadap bahasa dan budaya Arab, sebab Islam lahir di Arab dan al Quran berbahasa Arab (Muhajir, dalam Sahal \& Aziz, 2015: 62-63). Ide Islam Nusantara bukan untuk mengubah doktrin Islam, namun hanya mencari siasat membumikan Islam dalam konteks masyarakat yang plural (Ghazai dalam Sahal \& Aziz, 2015: 106). Pernyataan ini dapat menepis kecurigaan-kecurigaan orang-orang Islam sendiri yang selama ini menentang penggunaan istilah Islam Nusantara. Penggunaan istilah Islam Nusantara benar-benar steril dari rekayasa orang-orang non Islam, khususnya Barat. Pemunculan Islam Nusantara merupakan kreasi budaya Muslim yang digunakan memberikan alternatif cara-cara berpikir, cara memahami dan cara menjalankan Islam yang bermartabat. Cara yang demikian ini dapat diperhatikan pada Islam Nusantara ini sebagai contoh riil.

\section{Islam Indonesia Sebagai Percontohan}

Pemikiran, pemahaman dan pengamalan Islam di Indonesia ini menunjukkan kesejukan dan kedamaian, setidaknya bisa dilihat dari ekpresi 
kalangan mayoritas Muslim di negeri ini sebagai mainstream bagi umat Islam. Kesejukan dan kedamaian ini telah berlangsung berabad-abad yang lampau hingga sekarang ini, dan tidak tertarik untuk mengikuti fenomena-fenomena tindakan radikal yang berasal dari Timur Tengah yang meresahkan dunia. Mayoritas Muslim di negeri Jamrud Kathulistiwa ini justru berupaya menangkal tindakan-tindakan radikal tersebut dengan berbagai upaya, media dan saluran yang signifikan dan fungsional menyadarkan para pengikutnya.

Di samping itu, umat Islam Indonesia memiliki modal tambahan karena telah memiliki pengalaman berdemokrasi. Indonesia telah berhasil menerapkan demokrasi jauh mendahului negara-negara Muslim lainnya, baik dari segi waktu maupun kualitas. Maka mereka lebih dahulu terlatih bersikap terbuka, toleran, berinteraksi dengan pluralisme agama maupun budaya, dan menggunakan pendekatan kultural dalam mengembangkan ajaran-ajaran Islam, dibanding dengan umat Islam dari Negara-negara Muslim lainnya di kawasan mana pun di dunia ini (Qomar, 2012: 187). Pengalaman ini memperkuat eksistensi keislaman Nusantara ini yang senantiasa mengekpresikan keramahan, toleransi dan keterbukaan dalam menghadapi realitas-realitas pluralis.

Model pemikiran, pemahaman dan pengamalan Islam yang mampu menunjukkan kedamaian itu sekarang telah membuahkan hasil yang patut dibanggakan. Dalam pandangan dunia luar, Islam Indonesia menunjukkan wajah yang menarik dan karakter yang memikat sebagai rahmatan li al'alamin, jauh dari radikalisme dan ekstremitas yang melanda dunia dewasa ini. Bukan hanya umat Islam wilayah Timur yang mengagumi pendekatan keagamaan kita, Barat pun menunjuk Indonesia sebagai model alternatif bagi kerukunan antarumat beragama di permukaan bumi ini (Shihab, 1998: 335). Bila dibandingkan dengan negara-negara Muslim lainnya, umat Islam Indonesia lebih menyukai pemahaman pluralis tentang agama daripada pandangan establishmentarian. Melalui sejarah pengalaman yang panjang membangun kerukunan antaragama, antarsuku dan antarbudaya, Indonesia bisa menjadi contoh yang baik, bagi dunia Islam maupun dunia secara umum (Shihab, 1998: 348). Indonesia diharapkan menjadi contoh sebuah Islam yang damai, terbuka, dan moderat. Jika harapan ini terealisir, Islam Indonesia akan menjadi antitesis terhadap citra Islam yang sempat dirusak oleh kelakuan segelintir orang yang memilih jalan kekerasan (Maarif, 2009: 244).

Oleh karena itu, Islam Nusantara sebagai model berpikir, memahami dan mengamalkan Islam alternatif ini perlu diperkenalkan, disosialisasikan dan dipromosikan dalam skala nasional, regional, dan internasional. Kita 
harus berusaha mempromosikan manhaj Islam Nusantara ke seluruh dunia, khususnya pada bangsa-bangsa yang dilanda perang yang tak berhenti, yaitu mereka yang hanya bisa membuat kerusakan ( fasad) tetapi tidak melakukan perbaikan (shalah) (Muhajir dalam Sahal \& Aziz, 2015: 68). Promosi Islam Nusantara itu berbasis nilai dan norma keislaman yang dibangun lama sejak era rintisan para sufi. Islam yang tumbuh berkembang itu bercorak kompromistis dengan berbagai unsur lokal melalui proses asimilasi dan sinkretisasi (Fatoni, dalam Sahal \& Aziz, 2015: 236). Islam Nusantara itu success story dari Indonesia yang perlu disebarkan secara internasional (Nakamura, 2015: 30).

Islam Indonesia ini patut dipromosikan ke manca negara, karena umat Islam memiliki keistimewaan-keistimewaan tertentu. Berikut keistimewaan umat Islam Indonesia:

1. "Indonesia memiliki jumlah penduduk Muslim terbesar di dunia.

2. Jumlah umat Islam Indonesia masih lebih besar daripada jumlah gabungan umat Islam di Negara-negara Arab.

3. Indonesia memiliki wilayah terluas jika dibandingkan dengan negaranegara berpenduduk mayoritas Islam lainnya.

4. Geografis Indonesia berada pada posisi persimpangan transportasi.

5. Umat Islam Indonesia didukung oleh kebudayaan lembut (soft culture).

6. Wilayah Indonesia terdiri atas ribuan pulau dan lautnya lebih luas daripada daratannya yang memiliki kecenderungan terbuka.

7. Indonesia bebas dari konflik regional Timur Tengah.

8. Madhab yang berkembang di Indonesia sangat homogen (Sunni).

9. Madzhab Sunni yang dianut di Indonesia juga sangat membantu meringankan beban pemerintah menyatukan bangsa ini.

10. Indonesia menganut sistem demokrasi.

11. Indonesia sebagai negara Islam pertama yang melakukan pemilihan presiden secara langsung.

12. Kehadiran Departemen Agama yang mengurus dan melayani kepentingan umat beragama di Indonesia.

13. Keberadaan Pancasila sebagai falsafah bangsa terbukti sangat "sakti" mempersatukan bangsa Indonesia yang sangat majemuk dari berbagai segi.

14. Kekayaan alam Indonesia amat besar dan bervariasi.

15. Kesetaraan gender di Indonesia lebih maju daripada negara-negara Islam lainnya. 
16. Memiliki aneka ragam budaya yang menjadi warna-warna lokal ajaran Islam di Indonesia.

17. Adanya sistem pesantren sebagai salah satu lembaga pendidikan Islam tradisional yang memberi pengaruh penting di dalam masyarakat.

18. Kehadiran perguruan tinggi Islam, seperti UIN, IAIN, STAIN, dan PTAIS yang terhampar hampir di setiap provinsi bahkan kabupaten, memegang peranan penting dalam memberikan pencerahan terhadap umat.

19. Kehadiran ormas-ormas Islam seperti NU, Muhammadiyah dan ormasormas Islam lainnya ikut serta menciptakan kondisi yang baik bagi kelahiran suatu umat yang menjunjung tinggi pluralitas di dalam masyarakat.

20. Kehadiran Majlis Ulama Indonesia (MUI) juga menjadi faktor penting dalam memelihara kerukunan umat, baik kerukunan internal umat Islam, kerukunan antarumat beragama, maupun kerukunan antarumat beragama dengan pemerintah.

21. Faktor bahasa Indonesia sebagai bahasa pengantar dalam menyampaikan nilai-nilai dan ajaran Islam juga sangat menentukan" (Umar, 2014: 271276).

Demikianlah berbagai potensi yang dimiliki umat Islam Indonesia sebagai modal besar dalam menampilkan keberislaman mereka sebagai alternatif pemikiran, pemahaman dan pengamalan ajaran-ajaran Islam yang penuh kedamaian, keharmonisan dan kesejukan bagi umat Islam di seluruh dunia maupun umat-umat lainnya. Keberislaman demikian ini yang bisa menggugat dan mengubah pandangan maupun persepsi masyarakat dunia yang terlanjur salah terhadap Islam sebagaimana disebutkan di depan, yaitu Islam sebagai agama yang mengajarkan kekerasan, kekejaman, kekejian dan tindakan-tindakan radikal lainnya.

\section{Simpulan}

Dari paparan di atas dapat disimpulkan bahwa Islam Nusantara merupakan identitas Islam ditinjau dari segi kawasan, yang bisa disejajarkan dengan Islam Arab, Islam India, Islam Turki, dan sebagainya. Islam Nusantara ini merupakan model pemikiran, pemahaman dan pengamalan ajaran-ajaran Islam melalui pendekatan kultural, sehingga mencerminkan identitas Islam yang bernuansa metodologis. Islam Nusantara ini merefleksikan pemikiran, pemahaman, dan pengamalan Islam yang moderat, inklusif, toleran, cinta damai, menyejukkan, mengayomi dan menghargai keberagaman (kebinekaan) 
sehingga keberadaan Islam Nusantara tersebut sebagai antitesis terhadap tindakan-tindakan radikal yang mengatasnamakan Islam.

\section{Daftar Pustaka}

Ali, Mohamad. 2006. Islam Muda Liberal, Post-Puritan, Post-Tradisional. Yogyakarta: Apeiron Philotes.

Anam, Faris Khoirul. 2015. Mabadi 'Asyrah Islam Nusantara Memahami Sepuluh Prinsip Tema Peradaban Indonesia dan Dunia. Malang: Darkah Media.

Azhari, Muntaha dan Saleh, Abdul Mun'im, (Eds.). 1989. Islam Indonesia Menatap Masa Depan. Jakarta: P3M.

Azra, Azyumardi. 2015. Jaringan Islam Nusantara. Dalam Akhmad Sahal dan Munawir Aziz (Eds.), Islam Nusantara dari Ushul Fiqh hingga Paham Kebangsaan Bandung: Mizan.

Azra, Azyumardi. 2002. Islam Nusantara Jaringan Global dan Lokal, Bandung: Mizan.

Basya, M. Hilaly. 2007. Islam Moderat di Asia Tenggara. Dalam Hery Sucipto (Eds.), Islam Madzhab Tengah Persembahan 70 Tahun Tarmizi Taher. Jakarta: Grafindo Khazanah Ilmu.

Bizawie, Zainul Milal. 2015. Islam Nusantara Sebagai Subjek dalam Islamic Studies: Lintas Diskursus dan Metodologis. Dalam Akhmad Sahal dan Munawir Aziz (Eds.), Islam Nusantara dari Ushul Fiqh hingga Paham Kebangsaan. Bandung: Mizan.

Bruinessen, Martin Van. 2004. Post-Soeharto Muslim Engegement with Civil Society and Democratization. Dalam Hanneman Samuel \& Henk Schulte Nordholt (Eds.), Indonesia in Transition Rethinking 'Civil Society', 'Region', and 'Crisis'. Yogyakarta: Pustaka Pelajar.

Fanani, Ahmad Fuad. 2004. Islam Mazhab Kritis Menggagas Keberagaman Liberatif, Jakarta: Kompas.

Fatoni, Muhammad Sulton. 2015. NU dan Islam Nusantara. Dalam Akhmad Sahal dan Munawir Aziz (Eds.), Islam Nusantara dari Ushul Fiqh hingga Paham Kebangsaan. Bandung: Mizan.

Ghozali, Abdul Moqsith. 2015. Metodologi Islam Nusantara. Dalam Akhmad 
Sahal dan Munawir Aziz (Eds.), Islam Nusantara dari Ushul Fiqh hingga Paham Kebangsaan. Bandung: Mizan.

Hariwijaya, M. 2006. Islam Kejawen. Yogyakarta: Gelombang Pasang.

Huda, Nor. 2013. Islam Nusantara Sejarah Sosial Intelektual Islam di Indonesia. Yogyakarta: Arruzz Media.

Imarah, Muhammad. 2007. Islam Moderat Sebagai Penyelamat Peradaban Dunia. Dalam Hery Sucipto (Eds.), Islam Madzhab Tengah Persembahan 70 Tahun Tarmizi Taher. Jakarta: Grafindo Khazanah Ilmu.

Khalil, Ahmad. 2008. Islam Jawa Sufisme dalam Etika EB Tradisi Jawa. Malang: UIN Malang Press.

Langgulung, Hasan. 1989. Pendidikan Islam Indonesia: Mencari Kepastian Historis. Dalam Muntaha Azhari dan Abdul Mun'im Saleh (Eds.), Islam Indonesia Menatap Masa Depan. Jakarta: P3M.

Maarif, Ahmad Syafii. 2009. Islam dalam Bingkai Keindonesiaan dan Kemanusiaan Sebuah Refleksi Sejarah. Bandung: Mizan Bekerjasama dengan Maarif Institute.

Maarif, Ahmad Syafii. 1993. Peta Bumi Intelektualisme Islam di Indonesia. Bandung: Mizan.

Machasin. 2011. Islam Dinamis Islam Harmonis Lokalitas, Pluralisme, Terorisme. Abdul Wahid Hasan (Eds.). Yogyakarta: LkiS.

Madjid, Nurcholish. 1996. In Search of Islamic Roots for Modern Pluralism: The Indonesian Experiences. Dalam Mark R. Woodward (Eds.), Toward A New Paradigm Recent Developments in Indonesian Islamic Thought. Arizona: Arizona State University.

Muhajir, Afifuddin. 2015. Meneguhkan Islam Nusantara Untuk Peradaban Indonesia dan Dunia. Dalam Akhmad Sahal dan Munawir Aziz (Eds.), Islam Nusantara dari Ushul Fiqh hingga Paham Kebangsaan. Bandung: Mizan.

Muhammad, Husein. 2015. Hukum Islam yang Tetap dan yang Berubah. Dalam Akhmad Sahal dan Munawir Aziz (Eds.). Islam Nusantara dari Ushul Fiqh hingga Paham Kebangsaan. Bandung: Mizan. 
Nakamura, Mitsuo. September 2015. Kata Mereka Tentang Muktamar. Aula. 30.

Nakamura, Mitsuo. 1976. The Crescent Arises Over the Banyan Tree: A Study of the Muhammadiyah Movement in a Central Jawa Town. Ithaca: Cornell University.

Qomar, Mujamil. 2012. Fajar baru Islam Indonesia? Kajian komprehensif Atas Arah Sejarah dan Dinamika Intelektual Islam Nusantara. Bandung: Mizan.

R. Woodward, Mark. 1996. Talking Across Paradigms: Indonesia, Islam, and Orientalism. Dalam Mark R. Woodward (Eds.), Toward A New Paradigm Recent Developments in Indonesian Islamic Thought. Arizona: Arizona State University.

Rahmat, M. Imdadun. 2003. Islam Pribumi, Islam Indonesia. Dalam M. Imdadun Rahmat et al., Islam Pribumi Mendialogkan Agama Membaca Realitas. Sayed Mahdi dan Singgih Agung (Eds.). Jakarta: Erlangga.

Rahmat, M. Imdadun, et al. 2003. Islam Pribumi Mendialogkan Agama Membaca Realitas, Sayed Mahdi dan Singgih Agung (Eds.). Jakarta: Erlangga.

Ramadan, Tariq. 2010. The Quest for Meaning Developing a Philosophy of pluralism, London: The Penguin Group.

Sahal, Akhmad dan Aziz, Munawir (Eds.). 2015. Islam Nusantara dari Ushul Figh hingga Paham Kebangsaan. Bandung: Mizan.

Sahal, Akhmad. 2015. Prolog: Kenapa Islam Nusantara?. Dalam Akhmad Sahal dan Munawir Aziz (Eds.), Islam Nusantara dari Ushul Fiqh hingga Paham kebangsaan. Bandung: Mizan.

Saleh, Fauzan. 2005. Education and the Advancement of Cultural Islam: Rebuilding a Greater Tradition for Indonesian Islam. Dalam Alef Theria Wasim (Eds.), Religious Harmony: Problems, Practice and Education. Yogyakarta: Oais.

Shihab, Alwi. 1998. Islam Insklusif Menuju Sikap Terbuka dalam Beragama. Bandung: Mizan Bekerjasama dengan Anteve.

Sobarna, Ayi. 2008. Islam Positif Spirit Wacana Solusi Refleksi. Yogyakarta: Graha Ilmu. 
Sucipto, Hery (Eds.). 2007. Islam Madzhab Tengah Persembahan 70 Tahun Tarmizi Taher. Jakarta: Grafindo Khazanah Ilmu.

Sucipto, Hery. 2007. Pengantar Editor Tarmizi Taher dan Islam Madzhab Tengah. Dalam Hery Sucipto (Eds.), Islam Madzhab Tengah Persembahan 70 Tahun Tarmizi Taher. Jakarta: Grafindo Khazanah Ilmu.

Sychev, Victor Feodorovich. 2008. Islam Indonesia di Mata Orientalis Rusia. Terjemahan oleh Wan Jamaluddin Z. Jakarta: Balai Penelitian dan Pengembangan Agama Islam.

Umar, Nasaruddin. 2014. Islam Fungsional "Revitalisasi EO Reaktualisasi Nilai-nilai Keislaman”. Irsan Asari (Eds.). Jakarta: PT. Alex Media Komputindo.

Wijaya, Aksin. 2011. Menusantarakan Islam Menelusuri Jejak Pergumulan Islam yang Tak Kunjung Usai di Nusantara. Ponorogo: STAIN Po Press.

Yusuf, Choirul Fuad dan Haris, Tawalinuddin (Eds.). 2014. Inskripsi Islam Nusantara Jawa dan Sumatera. Jakarta: Puslitbang Lektur dan khazanah Keagamaan Badan Litbang dan Diklat Kementerian Agama RI.

el Harakah Vol.17 No.2 Tahun 2015 